\title{
Rituales mágicos en el Perú, según Ricardo Palma
}

\author{
César Coloma Porcari \\ Instituto Latinoamericano de Cultura y Desarrollo \\ Instituto Ricardo Palma de la Universidad Ricardo Palma \\ sillardearequipa@gmail.com
}

\section{Resumen}

Trabajo de investigación realizado en base a la información correspondiente a los rituales mágicos y supersticiones que proporciona don Ricardo Palma en sus Tradiciones Peruanas. Se presenta su valiosa opinión sobre este asunto y las precisas definiciones que ofrece sobre estos temas. Asimismo se incluye un glosario alfabético de términos referentes a las antiguas creencias, indicándose en qué tradición se encuentra la información, a la que se le agregan definiciones dadas por la Real Academia Española en siglos pasados y por otros autores.

Palabras clave: rituales, magia, religión, supersticiones, creencias.

\begin{abstract}
Research work carried out on the basis of the information corresponding to the magical rituals and superstitions that don Ricardo Palma provides in his Peruvian Traditions. His valuable opinion on this subject and the precise definitions offered about these issues is also presented in this essay. In addition, it includes an alphabetical glossary of terms referred to the ancient beliefs, that indicates in which "tradition" the information is found, adding the definitions given by the Royal Spanish Academy in past centuries and other authors.
\end{abstract}

Keywords: rituals, magic, religion, superstitions, beliefs. 
César Coloma Porcari, Economista, dedicado a la investigación histórica, ha publicado varios libros y centenares de artículos sobre el patrimonio cultural del Perú, en el diario El Comercio y en las revistas Caretas y Voces. Es Miembro de Número del Instituto Ricardo Palma y del Centro de Estudios Histórico-Militares del Perú; Miembro de Honor del Instituto Libertador Ramón Castilla; Miembro de la Sociedad Geográfica de Lima y de la Fundación Marina Núñez del Prado. Fue Director de Cultura de la Municipalidad de Lima Metropolitana, Director del Museo de Arte Italiano y del Museo Nacional de Historia, Director General del Centro Nacional de Información Cultural y actual presidente del Instituto Latinoamericano de Cultura y Desarrollo. Condecorado por la Universidad Católica de Santa María, de Arequipa, con la "Medalla Institucional", y por la Municipalidad Provincial de Arequipa, con la "Medalla de la Cultura". Ha recibido el grado de Doctor Honoris Causa. 
Don Ricardo Palma afirmaba que "El hombre es de suyo supersticioso. Todo lo fantástico y que encarna algo de maravilla le impresiona y atrae". Además, "Sólo civilizando a los pueblos, obteniendo que la razón domine sobre la fe, se conseguirá matar la superstición”. Por ello, “Desapareciendo esta, desaparecerá también el prestigio de la Roma papal. La base de su omnipotencia está en la ignorancia que esclaviza a la mayoría social" (Palma, 1968: 1430).

Palma, en la tradición que comentamos titulada "Supersticiones de los peruanos", recuerda además que el hombre precolombino fue supersticioso. Y "Vino la conquista. Y con ella el cristianismo (sic) con su idolátrico culto de las imágenes, sus risibles milagros y su inmenso cortejo de supersticiones". Entonces, "Estas cayeron sobre terreno fértil, y la raza indígena aumentó con ellas el caudal propio" (Ibidem), produciéndose un sincretismo religioso aún vigente en el Perú.

Casi todos los rituales mágicos mencionados en las Tradiciones del gran maestro vinieron de Europa con los conquistadores y varios subsisten en diversos lugares del Viejo Continente y en la América Latina. Y unos cuantos se originaron en estas tierras (agua "cuyana", cerros y lagunas encantados, coca, pasada del cuy, religión precolombina, y Santiago del Bien y Santiago del $\mathrm{Mal}$ ), habiendo sobrevivido algunos el paso del tiempo.

En este trabajo nos ocupamos, únicamente, de los rituales mágicos propiamente dichos y no nos referimos a las creencias religiosas impuestas por la Iglesia oficial, la Católica Romana, que don Ricardo Palma, como lo hemos visto, también las incluye entre las supersticiones de los peruanos.

Como ya lo hemos indicado, algunos rituales mencionados por el tradicionista, tanto los de origen europeo como los creados aquí, continúan vigentes hasta la actualidad. Y otros, muy 
comunes hoy, en los que se emplea la ruda (Ruta graveolens L.), la sábila (Aloe vera L.) o el cactus San Pedro (Trichocereus peruvianus Britton \& Rose), no son mencionados por Palma en sus Tradiciones.

Debemos tener presente que el Tribunal de la Santa Inquisición, establecido para combatir las "herejías" mediante torturas y la pena de muerte en la hoguera, también persiguió a brujos y adivinos. En "Anales de la Inquisición de Lima”, don Ricardo Palma da cuenta de los "autos de fe" que llevaba a cabo este Santo Tribunal. Por ejemplo, el realizado el 17 de noviembre de 1614, en el cual fue azotada en las calles, junto con otros penitenciados, doña María de la Cerda y Vadillo, llamada "la Tucumanesa, por hechicera" (Ibíd.: 1220).

En la misma obra, Palma se refiere al "auto de fe" realizado el 30 de noviembre de 1587. Uno de los "penitenciados" fue "Pedro Gutiérrez, quiteño, por nigromante". Y también registra el "auto de fe" llevado a cabo el 5 de abril de 1592, en que fueron "penitenciadas" "Ana de Castañeda, mulata panameña, y doña Isabel de Espinosa, natural de España, por hechiceras" (Ibíd.: 1222-1223).

El tradicionista (Ibíd.: 1243) afirma que:

Según Rodín, los brujos eran culpables de los enormes crímenes siguientes:

$1^{\circ}$ Reniegan de Dios.

$2^{\circ}$ Blasfeman.

$3^{\circ}$ Adoran al diablo.

$4^{\circ}$ Le dedican sus hijos.

$5^{\circ}$ Sacrifícanlos antes de ser bautizados.

$6^{\circ}$ Conságranlos a Satanás desde el vientre de la madre.

$7^{\circ}$ Juran en nombre del diablo y lo tienen a honra. 
$8^{\circ}$ Prométenle atraer cuantos puedan a su servicio.

$9^{\circ}$ Cometen incestos.

$10^{\circ}$ Matan a las personas, cocinan la carne y se la comen.

$11^{\circ}$ Mantiénense de carroña y de ahorcados.

$12^{\circ}$ Matan con el veneno y los sortilegios.

$13^{\circ}$ Hacen reventar el ganado.

$14^{\circ}$ Marchitan los frutos y causan la esterilidad de los campos.

$15^{\circ}$ Tienen ayuntamiento carnal con el diablo.

Palma, asimismo, afirma que "Llamábanse maleficios o sortilegios las enfermedades y otros accidentes desgraciados causados por el arte infernal" (Ibíd.: 1258).

Siete eran las principales especies de maleficio empleadas por los brujos:

$1^{\circ}$ Introducir en el corazón de un hombre un amor criminal por una mujer, y al contrario.

$2^{\circ}$ Inspirar sentimientos de odio o envidia a una persona contra otra.

$3^{\circ}$ Impedir que el matrimonio tenga prole.

$4^{\circ}$ Causar enfermedades.

$5^{\circ}$ Quitar el juicio.

$6^{\circ}$ Matar gente.

$7^{\circ}$ Aridecer los campos.

A continuación, ofrecemos los apuntes de don Ricardo Palma, en sus Tradiciones, referentes al ocultismo y rituales mágicos que menciona en sus Tradiciones, que hemos ordenado alfabéticamente:

\section{Agua cuyana}

En “Zurrón-currichi” (Ibíd.: 446-447), al referirse a una bruja de San Carlos de Puno que estaba preparando un hechizo, cuenta 
que esta "Probablemente no tuvo a mano (...) un botecito de agua cuyana, que en ese siglo [XVII] era todavía remedio infalible para hacerse amar". Y en "Los malditos" cuenta que:

En la provincia de Chachapoyas existió la fuente Cuyana (fuente de los amores), en la cumbre de un cerro escarpado, cuyo acceso era tan difícil que había necesidad de subir a gatas, y aun así se corría peligro de caer y despeñarse. La fuente tenía dos chorros: el agua de uno inspiraba amor por la persona que la deba a beber, y la del otro inspiraba aborrecimiento. (Ibid.: 237)

Además, "en 1610 los jesuitas destruyeron la fuente y extirparon la idolatría de que era objeto". Y “Tan popular debió ser la creencia en las virtudes de esa agua, que hoy mismo se dice, cuando una persona cambia la repugnancia en cariño: - iSi habrás bebido un traguito de la fuente Cuyana?”. (Ibíd.: 237)

\section{Aquelarre}

En "Anales de la Inquisición de Lima", capítulo VI (Ibíd., 1259), cuenta que:

En los aquelarres o reunión de brujos, en la noche del sábado, celebraba el diablo lo que llamaban la misa negra. Allí bautizaba el diablo niños y sapos. Los niños eran presentados, por la bruja su madrina, vestidos de terciopelo negro, y los sapos envueltos en terciopelo granate". La Real Academia Española, en 1914, define al aquelarre como "Conciliábulo de brujos o hechiceros.

Además señala que proviene del vascuence aquelarre, que proviene de "aquer, cabrón y larre, prado: prado del cabrón" (RAE, 1914: 85). 


\section{Astrología}

La Real Academia Española define, en 1817, a la Astrología, de esta manera: "Ciencia conjetural que enseña a juzgar los efectos e influencias de los astros, y a pronosticar los sucesos por la situación de los planetas y sus diferentes aspectos" (RAE, 1817: 99). Por su parte, el tradicionista, en "La astrología en el Perú" (Palma, 1968: 409-410), cuenta que en el siglo XVII, en el Perú, para "los médicos, cirujanos, boticarios y baberos", eran "artículos de fe y arte integrante de la ciencia", las "supersticiones astrológicas".

Palma menciona allí el libro "La astrología en la medicina", obra de don Juan de Figueroa, familiar del Santo Oficio de la Inquisición. Y cuenta que ese autor afirmaba que "cuando el Sol entra en el siglo de Aries", empeora la tisis, y "cuando domina Virgo, abundan los tumores en el vientre". Mientras que los dolores de cabeza dependen de Tauro; la sífilis, de Cáncer; los reumatismos, de Escorpio; las hidropesías, de Piscis; la ictericia, de Capricornio, "y así a cada signo del Zodiaco le adjudica el patronato de una dolencia” (Palma, 1968: 409-410).

Al comentar el libro mencionado, agrega que: "El que enfermaba, aunque fuera de un dolor de muelas, cuando ciertos signos que él apunta se hallasen de bureo en cierta casilla, no tenía otro remedio que mandar por mortaja y cajón, para hacerse enterrar". (Ibíd.: 409-410)

Asimismo:

Engendrar bajo la influencia de tales o cuales astros era para que el muchacho saliese un facineroso, o si era hembra, el engendro, una pelandusca. En cambio, todo el que se sujetase a las reglas astrológicas tendría los hijos con cualidades a medida del deseo. (Ibídem) 
Y Palma nos cuenta una serie de recomendaciones del autor del libro mencionado que hoy llaman la atención, pero que tuvieron "gran boga antaño". Cuenta también que en las casas siempre había un ejemplar "más manoseado que la Alfalfa espiritual para los borregos de Cristo y la bula de la Cruzada".

Palma concluye su narración diciendo que:

Tan rodeada de supersticiones y pueriles prácticas andaba la ciencia médica en Lima, que cuando el profesor de Anatomía se hallaba en el compromiso de dar a sus discípulos lección sobre el cadáver en el anfiteatro, antes de esgrimir cuchilla y escalpelo, rezaba, en unión de los presentes, una plegaria en latín por el alma del difunto. (Ibídem)

Nuestro célebre escritor manifiesta su incredulidad con respecto a la astrología, recogiendo esta redondilla:

El mentir de las estrellas

es muy seguro mentir,

porque ninguno ha de ir

a preguntárselo a ellas.

\section{Atar la agujeta}

En "Anales de la Inquisición de Lima", capítulo IV, cuenta que el Tribunal de la Fe acusó a la mulata arequipeña Sabina Rosalía de la Vega, de "atar la agujeta". Palma explica el significado de ello:

Cuando una mujer deseaba que su marido fuese impotente para con las demás, tomaba la aguja con que había sido cosida la mortaja de un cadáver y la escondía en una pieza del vestido del pobre hombre a quien maleficiaba. iA cuán poca costa se puede asegurar la fidelidad del sexo feo! (Palma, 1968: 1241) 
Y agrega que "Después de aprender esta habilidad, lectoras mías (...), os ruego que no os riais de la Santa Inquisición ni murmuréis del cronista que os la ha enseñado". (Ibidem)

También en "Anales de la Inquisición”, capítulo V (Ibíd.: 1250), se refiere a una bruja procesada por el santo Tribunal, que "sabía atar la agujeta". Y en "Las brujas de Ica" (Palma, 1968: 267), se refiere a una bruja que era "muy diestra" en "atar la agujeta".

\section{Brebajes}

En "Anales de la Inquisición de Lima", capítulo IV, (Ibíd.: 1240), cuenta que el Tribunal de la Fe acusó a la mulata limeña Micaela Zavala. Fue convicta y confesa, con auxilio del torno [tortura], de pacto con el diablo, quien la ayudó en la preparación de varios brebajes y hechizos para que los hombres la amasen. Y en "Franciscanos y jesuitas" (Ibíd.: 284-285), cuenta de una bruja que preparaba "filtros amorosos con grasa de culebra, sangre de chivo, sesos de lechuza, enjundias de sapo y zumo de cebollas estrujadas a la hora que la luna entra en conjunción". La bruja preparó un brebaje para que lo tomaran unos frailes jesuitas y otros franciscanos, que se encontraban en su posada. Este licor les hizo efecto rápidamente y los frailes se pusieron a bailar, de manera muy libidinosa, con las mozas que encontraron en la posada.

\section{Campanillas}

En "Anales de la Inquisición de Lima", capítulo III, (Ibíd.: 1233), narra la historia de la beata agustina Ángela Carranza, procesada por el santo Tribunal. Allí el tradicionista afirma que ella "Regalaba y vendía rosarios, velas, espadas, cuentos, campanillas y romero, como bendecidos por el cielo, y suponiendo que gozaban de ciertos privilegios”. Don Sebastián de Covarrubias, en 1611, define este término así: "Campanillas, 
diminutivo de campanas. El sumo sacerdote traía colgando del ruedo de la vestidura ciertas campanillas de oro". Y "En algunas partes se usan unas ruedas de campanillas que se tañen al alçar" (sic) (Covarrubias, 1611: 183).

\section{Cebolla albarrana}

La Real Academia Española define la cebolla albarrana como "Yerba medicinal, cuyas hojas son de un verde hermoso, anchas y jugosas, y la raíz parecida a la de la cebolla, con los cascos más gruesos, viscosos, muy acres y amargos". Su nombre científico es Scilla marítima L." (RAE, 1817: 191). Y en "De cómo desbanqué a un rival" (Palma, 1968: 1439), Palma cuenta que un personaje le ofreció a una dama llevarla donde una bruja. Ella les hizo "el ensalmo" de la "cebolla albarrana", y "todas las habilidades que ejecuta cualquiera bruja de tres al cuarto".

\section{Cedazo, sortijas y tijeras}

En "De cómo desbanqué a un rival" (Ibíd.: 1439), un personaje le ofrece a una dama llevarla donde una bruja. Ella les "hizo la brujería de las tijeras, la sortija y el cedazo". Y en "Anales de la Inquisición de Lima", capítulo VI (Ibíd.: 1259), cuenta que para que un niño estuviera "libre de todo daño", "bastaba con que el cura al bautizarlo no equivocase un solo latinajo". Y para comprobarlo, "recurría el supersticioso pueblo a un cedazo". Y a la medianoche del sábado, cuando las brujas estaban en el aquelarre, "se hacían sobre el cedazo tres cruces con la mano izquierda, y se le suspendía en el aire cogido por el aro con las puntas de unas tijeras. Si el cedazo empezaba a girar, era clara prueba de que el cura no había escrupulosamente llenado su ministerio". 


\section{Cerros y lagunas encantados}

En "Supersticiones de los peruanos" (Ibíd.: 1432), afirma que "Los indios creen en los encantamientos. En tal cerro, en tal laguna, en tal monte hay encanto, dicen; y cuentan la leyenda en la que, por tradición, se fundan para afirmarlo".

\section{Coca}

La Real Academia Española, en 1914, define a la coca (Erythroxylum coca Lamarck) como "Arbusto del Perú, de la familia de las eritroxíleas, con hojas alternas, aovadas, enteras, de estípulas axilares y flores blanquecinas. Se cultiva en varias partes de la América del Sur, donde se toma el cocimiento de las hojas como el té o el café; en lo antiguo fueron estas objeto de muchas supersticiones, y los indios gustan de mascarlas" (RAE, 1914: 242).

Don Antonio Raimondi, al referirse a las hojas de coca, indica que estas "unidas a un poco de cal son empleadas por los indios para mascar y les sirven para suplir el alimento por el espacio de un día", y afirma además que la coca "tiene propiedades excitantes" (Raimondi, 1857: 256-257).

En "Supersticiones de los peruanos" (Palma, 1968: 1431), el tradicionista afirma que hay hechiceros que "toman un puñado de coca, la esparcen sobre un pañuelo o camisa del enfermo, y después de invocar a Jesucristo y a tales o cuales santos, soplan la coca y diagnostican según la dirección que han tomado las hojitas".

\section{Cuentas mágicas}

La Real Academia Española, en 1817, define a las cuentas como "cada una de las bolitas ensartadas que componen el rosario, y 
sirven para llevar la cuenta de las oraciones que se rezan; y por semejanza, cualquiera bolilla ensartada" (RAE 1817: 261). Y en "Anales de la Inquisición de Lima", capítulo III, (Palma, Op. Cit.: 1233), narra la historia de la beata agustina Ángela Carranza, procesada por el santo Tribunal. Allí el tradicionista afirma que para ella, las cuentas "de Loyola" servían "para ahuyentar al diablo", mientras que las cuentas "de San Andrés" eran "para la locura"; las cuentas "de San Jerónimo tenían virtud para convertir infieles"; las "de San José servían para guardar castidad", las "de San Juan" eran útiles "contra la peste, mal de corazón y sobrepartos", y las "de San Miguel" servían "para que no entren ladrones en casa".

\section{Dios y el sacerdote}

En "Supersticiones de los peruanos" (Ibid.: 1430), afirma que "los indios, en medio de sus infinitas supersticiones y prácticas gentílicas, son altamente fanáticos. No hacen diferencia entre Dios y el Cura que los explota a su sabor. Puede decirse que trabajan solo para este, y cuánto ganan va a parar al bolsillo simoniaco del sacerdote católico".

\section{Domingo siete}

El tradicionista en "Refranero, IV": "Salir con un domingo siete" (Ibid.: 1 186-1 187), se refiere a un cuento alemán que trata de una aldea en la cual todas las mujeres eran brujas. Ellas celebraban la "misa negra", los sábados, en un bosque. A esta "asistía el diablo disfrazado de macho cabrío". Cuenta, además, que eran vecinos de esa aldea "dos jorobados", uno de los cuales se perdió y se refugió en el bosque. Él vio allí que a la medianoche, "cabelleras en cañas y escobas, llegaron las madamas, y empezó el aquelarre, y vino la misa, y siguió el bailoteo". 
Luego, "Las brujas, tomadas de las manos, formaron rueda, en cuyo centro se plantó Cachirulo [i.e. el diablo], y removieron los pies y el taleguillo de pecados". Y cantaron:

\section{Lunes y martes \\ miércoles tres"}

El jorobado perdido "pensó que la copla estaba inconclusa, y que sería oportuno redondearla". Y gritó "desde su escondite":

$$
\begin{gathered}
\text { Jueves y viernes, } \\
\text { sábado seis. }
\end{gathered}
$$

Los asistentes al aquelarre quedaron muy satisfechos y aplaudieron al intruso. Hasta el Diablo estuvo feliz. Y las brujas decidieron curarle la joroba al aldeano, en señal de agradecimiento. Y este, "más enhiesto que la vara de la justicia", regresó a su aldea y le contó lo ocurrido al otro jorobado. Este se fue al bosque en noche de aquelarre, y mientras las brujas cantaban:

$$
\begin{gathered}
\text { Lunes y martes } \\
\text { miércoles tres; } \\
\text { jueves y viernes, } \\
\text { sábado seis. }
\end{gathered}
$$

El nuevo intruso "gritó con toda la fuerza de sus pulmones":

$$
\text { iDomingo, siete! }
$$

Entonces, las brujas se indignaron con esta intervención, ya que el agregado no rimaba. Buscaron al aldeano y en castigo, a la joroba que tenía como propia, le agregaron la que le habían quitado a su compañero. Por ello, "cuando cae en siete el primer domingo de un mes, dice el pueblo: 'Con qué domingo siete nos saldrá este mes', que es como vivir prevenido a que no le coja a uno de nuevo 
un cataclismo o una crisis ministerial, de esas que entre nosotros concluyen en un domingo siete; esto es, la forma menos prevista".

\section{Epidemias}

El tradicionista, en "Anales de la Inquisición de Lima”, capítulo VI, (Ibíd.: 1258), afirma que para la Santa Inquisición, "todos los males a que está sujeta la especie humana serían obras de brujas". Y "Hasta las epidemias se miraban como maleficios".

\section{Escobas}

En "Anales de la Inquisición de Lima", capítulo VI (Ibíd.: 1259), cuenta que "Una escoba, colgada detrás de una puerta, con las palmas hacia arriba, era el mejor centinela posible para impedir que de noche entrasen brujas en una alcoba a chuparle el tuetanillo a los infantes". Y en "Justos y pecadores" (Ibíd.: 336-337), menciona a una dama que "se emperejilaba los sábados para asistir con su tío, montada en una caña de escoba, al aquelarre de las brujas".

Asimismo, en "Refranero, IV": "Salir con un domingo siete" (Ibíd.: 1186-1187), se refiere a una misa negra y a las brujas que asistieron a esta. A la medianoche, "caballeras en cañas y escobas, llegaron las madamas, y empezó el aquelarre, y vino la misa, y siguió el bailoteo".

\section{Espadas}

En "Anales de la Inquisición de Lima", capítulo III, (Ibíd.: 1233), narra la historia de la beata agustina Ángela Carranza, procesada por el santo Tribunal. Allí el tradicionista afirma que ella "Regalaba y vendía rosarios, velas, espadas, cuentos, 
campanillas y romero, como bendecidos por el cielo, y suponiendo que gozaban de ciertos privilegios".

\section{Frailes degolladores de enfermos}

Palma, en "Los barbones", se refiere a los sacerdotes pertenecientes a la orden betlemita, que tenía a su cargo varios hospitales en este reino del Perú (Ibíd.: 441). Y nos cuenta que en el Cuzco, los indígenas creían que "los betlemitas degollaban a los enfermos para sacarles las enjundias y hacer manteca para las boticas de Su Majestad". Por ello, cuando encontraban en la calle a un fraile de la Orden de Nuestra Señora de Belén, le gritaban “iNaca! iNaca! (degolladores o verdugos)" y "lo colmaban de injurias, le tiraban piedras, y aún sucedió, que por equivocación, mataron a un religioso de otra Orden".

\section{Gallina negra}

En "Anales de la Inquisición de Lima", capítulo VI, cuenta que los hechiceros, "por una gallina negra dan el oro y el moro. No hay bruja que en su corral no posea, por lo menos, un par de esas gallinas". Asimismo, para el "pacto con el demonio" hacían un ritual "degollando una gallina negra y enterrándola con ciertas ceremonias y palabras mágicas” (Ibíd.: 1259).

\section{Gallo}

Asimismo, en sus "Anales de la Inquisición de Lima", capítulo VI, cuenta que "Los brujos experimentan gran aversión por el gallo, pues el canto de este obra para dispersar el aquelarre" (Ibíd.: 1259). El canto del gallo anunciaba el nuevo amanecer y con este, el fin de las tinieblas. 


\section{Hechizo}

Don Sebastián de Covarrubias, en 1611, define al hechizo como "cierto género de encantación con que ligan a la persona hechizada, de modo que le pervierten el juicio, y le hazen querer lo que estando libre aborrecería. Esto se haze con pacto del demonio expresso o tácito" (sic) (Covarrubias, 1611: 465).

En "Zurrón-currichi” (Palma 1968: 446-447), cuenta de una bruja de San Carlos de Puno, llamada doña Valdetrudes, que le encargó al barbero le consiguiera un mechón de cabello de un personaje del lugar. El barbero no cumplió con el pedido, pero, al pasar por una tienda para comprar cocos y nueces, "detúvose delante de dos zurrones de piel de cabra, y con las tijeras, que en la mano traía, cortó de cada uno un poco de pelo". Esto se lo llevó a la bruja, a su casa, quien "echando llave y cerrojo, púsose a invocar al diablo y a preparar el hechizo". Palma dice que no sabe "qué clase de menjurje o filtro confeccionó" la bruja.

Y una vez hecho el hechizo, salió la bruja a buscar al hombre que deseaba, y lo encontró "en la puerta de su tienda". Entonces, "de repente, y cuando doña Valdetrudes no habría adelantado media cuadra, un zurrón de nueces y otro de cocos empezaron a bailar la zarabanda corriendo tras la bruja". Ella, asustada, apuró más el paso, pero era perseguida por los dos zurrones, que por lo visto se habían enamorado de ella, y no se detenían. Luego de esta estrepitosa carrera, los tres "fueron al fin a sumergirse para siempre en el Titicaca". De ahí el dicho "puneña, zurrón-currichi".

En "Anales de la Inquisición de Lima”, capítulo IV, (Ibíd.: 1240), cuenta que el Tribunal de la Fe acusó a la mulata limeña Micaela Zavala. Fue convicta y confesa, con auxilio del torno [tortura], de pacto con el diablo, quien la ayudó en la preparación de varios brebajes y hechizos para que los hombres la amasen. 


\section{Herraduras}

En "Contra pereza, diligencia" (Ibíd.: 1090-1092), Palma se refiere a "una viejecita que se llamada doña Quirina, y que (...) vivía pared por medio de mi casa". Ella tenía una urna de cristal en la que conservaba un Nacimiento. El tradicionista cuenta que lo que más le llamaba la atención era "una tosca herradura de fierro tachonada con lentejuelas de oro, que en el fondo de la urna se destacaba como sirviendo de nimbo a un angelito mofletudo".

Agrega que:

Doña Quirina era supersticiosa. No creía, ciertamente, que llevar consigo un pedacito de cuerda de ahorcado trae felicidad; pero tenía por artículo de fe que en casa donde se conserva con veneración una herradura mular o caballar no penetra la peste, ni falta pan, ni se aposenta la desventura. (Ibídem)

Y Palma narra, jocosamente, el origen de la superstición de las herraduras, que dice le contó doña Quirina. Jesucristo estaba con San Pedro y "tropezó en su camino con una herradura mohosa". Le ordenó al Santo que la recogiera, pero no le obedeció, diciéndole que "Facilito es que yo me agache por un pedazo de fierro viejo".

Jesucristo, entonces, recogió la herradura y continuaron su camino. En una aldea se la vendió a un herrero, quien le pagó dos centavos. Con estos, compró dos docenas de cerezas, "con más una de yapa". Siguieron andando y el calor era insoportable. San Pedro tenía mucha sed "y habría dado el oro y el moro por un poco de agua". "El Señor, de rato en rato, metía la mano en la manga y llevaba a la boca una cereza". Pero "dejaba caer otra". Esto ocurrió seis veces, y San Pedro, "sin hacerse el remolón, se agachaba a recoger, engulléndosela en el acto". Entonces 
Jesucristo le dijo a San Pedro: "Ya lo ves, Pedro: por no haberte agachado una vez, has tenido que hacerlo seis. Contra pereza, diligencia”. (Ibídem)

\section{Laboratorio de una bruja}

Palma, en "De cómo desbanqué a un rival", describe "el laboratorio o salita de aparato" de una bruja: "Había sapos y culebras en espíritu de vino, pájaros y sabandijas disecados, frascos con agua de colores, ampolleta y esqueleto; en fin, todos los cachivaches de la profesión". Además, "La lechuza, el gato y el perro empajados no podían faltar: son de reglamento, como el murciélago sobre un espejo y la lagartija entro de una olla" (Ibíd.: 1439).

\section{Lectura de las manos}

La lectura de las manos o Quiromancia es mencionada en "De cómo desbanqué a un rival" (Ibíd.: 1439). Allí un personaje le ofrece a una dama llevarla donde una bruja, diciéndole que "por cuatro o cinco duros te leerá el porvenir en las rayas de las manos". Asimismo, en "Anales de la Inquisición de Lima", capítulo II (Ibíd.: 1223), informa sobre el "auto de fe" realizado el 5 de abril de 1592, en que fue "penitenciado" "Francisco López, porque, examinándole las rayas de la mano, pronosticó en un garito, a otro jugador, próxima y aciaga muerte". La Real Academia Española defina a la Quiromancia como "Adivinación vana y supersticiosa por las rayas de las manos" (RAE, 1914, 857).

\section{Lectura de las cartas}

El tradicionista, en "De cómo desbanqué a un rival" (Palma, 1968: 1439), se refiere a la Cartomancia. Un personaje le sugiere a una dama llevarla donde una bruja, la cual "por cuatro o cinco 
duros te leerá (...) el pasado en el libro de las cuarenta" [i.e. la baraja de naipes]. Llegaron a la casa de la bruja y ella les "jugó la baratija". Y en "El aviso" (p. 798) se refiere a "una adivina, echadora de cartas, algebrista de voluntades y propinadora de menjurjes y panaceas, sin que la Policía ni la Facultad de Medicina pongan coto al libre ejercicio del embaucador y funesto charlatanismo". La Real Academia Española define a la Cartomancia como "Arte vano y supersticioso de adivinar el futuro por medio de los naipes" (RAE, 1914: 211 ).

\section{Mano de gloria}

En "Anales de la Inquisición de Lima”, capítulo IV, (Palma 1968: 1241), cuenta que el Tribunal de la Fe acusó a la mestiza chilena María Hernández, de "maestra de hechicerías". En su casa encontraron "lo que los brujos llaman mano de gloria, es decir, la mano de un ahorcado sirviendo de candelero". En cuanto a esto, debemos tener presente que "Atribuíase a semejante luz el poder de inmovilizar a las personas a quienes alumbrase. Esto, como se comprende, no pasa de ser una fantástica pretensión tan insostenible como las otras varias que le adjudican diversos grimorios" (Maestri, 1956: 418-419).

\section{Misa negra}

En “La misa negra” (Palma, 1968: 834), el tradicionista cuenta que el "padre Pardiñas" decía que la misa negra era:

La que celebra el diablo, en figura de macho cabrío, con unos cuernos de a vara y más puntiagudos que aguja de colchonero. La hostia es un pedazo de carroña de cristiano, y con ella da la comunión a los suyos. 
En Lima acostumbraban los brujos hacer sus misas negras en el cerrito de las Ramas, burlando a la Santa Inquisición. Asimismo, en "Anales de la Inquisición de Lima", capítulo VI (Ibíd.: 1259), cuenta que "En los aquelarres o reunión de brujos, en la noche del sábado, celebraba el diablo lo que llaman la misa negra".

\section{Muñecos de cera y trapo}

Don Ricardo Palma, en "Anales de la Inquisición de Lima", capítulo IV, cuenta que el Tribunal de la Fe acusó a la mulata arequipeña Sabina Rosalía de la Vega, de "componer figuritas de cera para atraerse a los hombres". Y en "Franciscanos y jesuitas" (Ibíd.: 284-285), menciona a una bruja que "se ocupaba de clavetear con alfileres un muñeco de trapo, dentro del cual había puesto, a guisa de alma, un trozo de rabo de lagartija" (Ibíd.: 1241). También en "Anales de la Inquisición", capítulo V (Palma, 1968: 1250), se refiere a una bruja procesada por el santo Tribunal, que "embargaba la voz" de una persona "con una espina que atravesaba en la garganta de una figura de cera".

Asimismo, en "Las brujas de Ica" (Ibíd.: 267-268), se refiere a una bruja que era "muy diestra" en "alfiletear muñecos". Ella, cuando atendía a un enfermo, "Cortábale en seguida un trozo de vestido o un mechón de pelo (...), a fin de sacar muñeco". Y al día siguiente llevaba al enfermo al campo, y allí "desenterraba una figurilla de trapo claveteada de alfileres”. La bruja le decía que "si no sanaba era porque había recurrido tarde a la ciencia de la hechicera".

\section{Niño pellizcado}

En "La procesión de ánimas de San Agustín" (Ibíd.: 487-488) se refiere a una procesión similar, que salía de la iglesia de la Soledad. Un día, "habiéndose asomado a verla cierta vieja 
grandísima pecadora", cada fraile difunto que pasaba por su puerta le entregaba un cirio para que lo guardara "hasta mañana”. La anciana decidió vender, al día siguiente, el centenar de cirios que le habían dejado los curas muertos. Pero, cuando amaneció esas velas se habían convertido en canillas humanas. Entonces, fue a confesarse con un sacerdote y él "le aconsejó que escondiese bajo el manto un niño recién nacido, y que lo pellizcase hasta obligarlo a llorar cuando se presentara la procesión". Así lo hizo la mujer y "gracias al ardid no se la llevaron las ánimas benditas por no cargar también con el mamón, volviendo las canillas a convertirse en cirios que iba devolviendo a sus dueños".

Palma dice, a guisa de burla, que:

Francamente, no puede ser más prosaico este siglo diecinueve en que vivimos. Ya no asoma el diablo por el cerrito de las Ramas, ya los duendes no tiran piedras ni toman las casas por asalto, ya no hay milagros ni apariciones de santos y ni las ánimas del purgatorio se acuerdan de favorecernos siquiera con una procesioncita vergonzante. Lo dicho: con tanta prosa y con el descreimiento que nos han traído los masones, está Lima como para correr de ella. (Ibídem)

\section{Número 13}

En "Un virrey y un arzobispo" (Ibíd.: 565), al referirse a las supersticiones, dice que "la preocupación nunca es tan palmaria como cuando se trata del número 13". Asimismo, "Los devotos explican que la desgracia del 13 surge de que Judas completó este número en la divina cena". Y "Otra de las particularidades del 13, conocido también como docena de fraile, es la de designar las monedas que se dan en arras", al contraer matrimonio. 
Aún en la actualidad hay personas que creen que el trece es un "Número fatal que inspira generalísimo terror en muchos pueblos de las naciones orientales y occidentales". Además, "En las mesas cuídase de que no se reúnan trece convidados, iy cuántas veces hemos oído decir que el comensal número trece es el que la suerte designa para morir el primero de todos los reunidos en una comida!" (Maestri, 1956: 588).

\section{Oración del Justo Juez}

En "Refranero, III": “iFíate del Justo Juez y no corras!" (Palma, 1968: 1185), cuenta que estuvo en el Real Felipe del Callao, como presidiario, por razones políticas, y menciona a un famoso bandido, llamado "Viborita", que tenía mucha fe en "esos escapularios que trabajan las monjas del Carmen", en donde guardaba la "Oración del Justo Juez". Palma dice que:

A la letra copio para satisfacción de curiosos que han oído y oyen hablar de tal amuleto

Hay leones que vienen contra mí.

Deténganse en sí propios, como se detuvo mi Señor Jesucristo

y le dijo al Justo Juez:

- iEa, señor! A mis enemigos veo venir,

$\mathrm{y}$ tres veces repito:

ojos tengan, no me vean;

boca tengan, no me hablen;

manos tengan, no me toquen;

pies tengan, no me alcancen.

La sangre les beba y el corazón les parta.

Por aquella camisa

en que tu Santísimo Hijo fue envuelto, me he de ver libre de malas lenguas, de prisiones, de hechicerías y maleficios, para lo cual me encomiendo a todo lo angélico y sacrosanto, 
y me han de amparar los Santos Evangelios,

y llegaréis derribados a mí

como el Señor derribó el día de Pascua a sus enemigos.

Y por la Virgen María y Hostia consagrada

que me he de ver libre de prisiones,

ni seré herido, ni atropellado,

ni mi sangre derramada,

ni moriré de muerte repentina.

Dios conmigo, yo con Él;

Dios delante, yo tras Él.

Jesús, María y José.

El delincuente trató de huir del presidio y en una escaramuza con los soldados de la guardia, fue muerto de un balazo. Palma comenta que "Con el ejemplo de Viborita hay de sobra para perder la fe en la eficacia y virtudes de la oración o amuleto". Y agrega que "Él la llevaba sobre el pecho como coraza que lo premunía contra las balas traidoras, y otro gallo le habría cantado si hubiese fiado la salvación a la ligereza de sus pinreles más que a la tan famosa oracioncita del Justo Juez".

\section{Oración de la piedra imán}

En "Refranero, III": “iFíate del Justo Juez y no corras!" (Ibíd.: 1185-1186), dice:

Y ya que he dado a conocer la famosa oración del Justo Juez, no creo fuera de lugar hacer lo mismo con la que, envuelta en un trozo de piedra imán, usan los enamorados, los rateros y ladrones de baja estofa. Dice así la Oración de la piedra imán:

Poderosa piedra imán

que entre mármoles naciste,

y la arenilla comiste 
en el río del Jordán, donde te dejó San Juan, acero debías vencer $\mathrm{y}$ al mismo aire substraer luego te cogió San Pedro, que estaba bajo de un cedro, para extender su virtud, y con muy crecida luz dijo que excelente fueras. Si un viviente te cogiera, ha de quedar victorioso y llamarte muy dichoso con tu preciosa virtud, siempre que te haga la cruz o te tenga encajonada y siempre reverenciada en donde no te dé el sol; pues Dios mismo te dotó para que sola parieses y que otra piedra no hubiese al igual de tu nación. Consígame tu oración acertado entendimiento para conseguir mi intento, siguiendo con devoción, piedra imán del corazón, piedra imán de mi alegría, a Jesús, José y María.

\section{Pacto con el diablo}

En "Anales de la Inquisición de Lima", capítulo VI (Ibíd.: 1259), dice que "En cuanto al pacto con el demonio, varios eran los modos de realizarlo. Hacíasele aparecer pronunciando 
cierto conjuro o degollando una gallina negra y enterrándola con ciertas ceremonias y palabras mágicas". Además, "Cuando el diablo tenía a bien mostrarse, se extendía el contrato en pergamino y se confirmaba con sangre". Y, "el diablo se avenía a todo, siempre que no faltase la condición de entregarle el alma después de la muerte".

\section{Pasada del cuy}

En "La venganza de un cura" (Ibíd.: 1105) cuenta de un sacerdote que les suministró un veneno a unos enemigos suyos. Estos padecieron de "horribles dolores de estómago" y en un pueblo vecino, una curandera "Dióles a beber no sé qué brebaje, aplicóles al vientre un cui negro (sic), hízoles aspirar humo de lana de carnero mocho y les aseguró que sanarían como por ensalmo".

Y en "Supersticiones de los peruanos" (Ibíd.: 1430-1431), afirma que cuando el enfermo no se curaba con las hierbas medicinales que le suministraban, se recurría al brujo del lugar. Este le pasaba el cuy (Cavia porcellus L., Cavia cobayo). Para ello

Fricciona con él el cuerpo del enfermo, y si al pasarlo por el estómago, frente o pulmones, grita el animal, declara el brujo que esta es la parte afectada o enferma, que el individuo ha sido hechizado y que antes de comprometerse a curarlo necesita consultar por la noche a las estrellas.

\section{Pernada}

Palma, en "Supersticiones de los peruanos" (Ibíd.: 1430), afirma que "Hay pueblos en los que las novias, desde ocho días antes de contraer matrimonio, son depositadas en casa del cura, y a nadie escandaliza el que este cobre derecho de pernada como los antiguos señores feudales". La Real Academia Española, en 1914, 
define la pernada así: "Derecho que se atribuían ciertos señores feudales, de entrar en el lecho de la desposada antes que el marido, y que se rescataba por una suma de dinero" (RAE, 1914: 788).

\section{Piedra imán}

En “Zurrón-currichi” (Palma, 1968: 446-447), cuenta la historia de una bruja de San Carlos de Puno diciendo que "pues eso de enredar pelos en piedra imán para hacerse amar de un hombre es propio de brujillas de tres al cuarto y no de catedráticas". Y en "De cómo desbanqué a un rival" (Ibíd.: 1439), le ofrece a una dama llevarla donde una bruja. Ella les hizo "el ensalmo de la piedra imán", y "todas las habilidades que ejecuta cualquiera bruja de tres al cuarto". La Real Academia Española, en 1914, define al imán como "Mineral de hierro de color negruzco, opaco, casi tan duro como el vidrio, cinco veces más pesado que el agua, y que tiene la propiedad de atraer el hierro, el acero y en grado menor algunos otros cuerpos".

\section{Purificación}

En "Supersticiones de los peruanos" (Ibíd.: 1434), afirma que para que una viuda se vuelva a casar, debía pasar por un proceso de "purificación", que consistía en bañarla desnuda en un río, en presencia de sus parientes. Y "complemento de la purificación es una orgía, en la que la mujer llega a pertenecer a tres hombres, de los que uno representa al Padre Eterno y los otros dos a San Pedro y San José". Por último, "Después de purificada así, es seguro que encontrará nuevo marido".

\section{Ramas de olivo}

En "Desdichas de Pirindín" (Ibíd.: 591), Palma se refiere a las ramas de olivo (Olea europæa L.), y cuenta la historia de un vecino 
del Cerro de Pasco, llamado don Lesmes Pirindín, que "tiene pacto con el diablo o es Satanás en persona”. Este personaje,

Una noche, visitó a la amiga de otro vecino acaudalado. Él iba muy sí señor y muy en ello a pisar el umbral, cuando de improviso y como mordido de víbora, dio un brinco hasta la pared del frente. Había tropezado en el quicio de la puerta con una ramita de olivo, bendecida por el cura el Domingo de Ramos.

No le fue bien en la aventura y luego de otros reveses, abandonó el Cerro de Pasco, diciéndole "iTierra ingrata! No eres digna de mí. Verdad que tampoco te hago falta, porque llevas en tu seno tres pecados capitales, y ya vendrán los restantes. iAbur! iHasta nunca!".

\section{Religión precolombina}

Palma, en "Anales de la Inquisición de Lima", capítulo VI, (Ibíd.: 1263), cuenta que el Santo Tribunal ordenaba a los fieles católicos que denunciaran a los que "hagan hechizos con las hojas de la coca, o que adoren ídolos de los Incas y al Sol, o que entierren en huacas a los difuntos".

\section{Reliquias}

Cuenta el tradicionista en "El porqué fray Martín de Porres, Santo limeño, no hace ya milagros" (Ibíd.: 366-367), que cuando murió fray Martín, en 1639:

Nadie se quedó en la tierra sin reliquia de un retacito del hábito o de la camisa, o por lo menos sin una pulgarada de tierra traída de la sepultura, tierra que guardaban en un saquito de terciopelo, y que a guisa de relicario llevaban los crédulos devotos, pendiente del cuello. Esta tierra diz que era eficaz específico contra la diarrea". Pero, "Con el correr del tiempo las reliquias fueron al basurero. 
Asimismo, cuenta en "La capa de San José" (Ibíd.: 484), que en el monasterio de las Descalzas de Lima tenían una reliquia muy importante: la capa de San José. Decían que esta reliquia curaba "cólicos misereres, zaratanes, tabardillos y pulmonías".

\section{Romero}

En "Anales de la Inquisición de Lima", capítulo III, (Ibíd.: 1233), narra la historia de la beata agustina Ángela Carranza, procesada por el santo Tribunal. Allí el tradicionista afirma que ella "Regalaba y vendía rosarios, velas, espadas, cuentos, campanillas y romero, como bendecidos por el cielo, y suponiendo que gozaban de ciertos privilegios". El nombre científico del romero es Rosmarinus officinalis L.

\section{Rosarios}

En "Anales de la Inquisición de Lima", capítulo III, (Ibíd.: 1233), se refiere a la beata Ángela Carranza, procesada por el Tribunal de la Fe. Allí el tradicionista afirma que ella "Regalabay vendía rosarios, velas, espadas, cuentos, campanillas y romero, como bendecidos por el cielo, y suponiendo que gozaban de ciertos privilegios". Y en "Una hostia sin consagrar" (Ibíd.: 638), menciona unos "rosarios de cuentas azules, como amuleto para las paperas, coto y demás enfermedades de garganta”.

La Real Academia Española, en 1914, define al rosario como "Sarta de cuentas, separadas de diez en diez por otras más gruesas y anudada por sus dos extremos a una cruz, precedida, por lo común, de tres cuentas pequeñas" (RAE, 1914: 906). 


\section{Rueda de Santa Catalina}

Palma, en "Anales de la Inquisición de Lima", capítulo II (Ibíd.: 1222-1223), se refiere al auto de fe realizado el 30 de noviembre de 1587. Uno de los “penitenciados" fue "el español Juan Pablo de Borja, que se jactaba de poseer la rueda de Santa Catalina para practicar brujerías".

Esta "rueda de Santa Catalina" representa el instrumento de tortura al que fue sometida la Mártir Santa Catalina de Alejandría. Siempre ha sido un símbolo empleado en el ocultismo, y es "La que los saludadores se hacen estampar en alguna parte del cuerpo, y blasonan muchas veces tener impresa en su paladar", y también, "En los relojes la que hace mover el volante, y tiene los dientes a modo de navajas". El "saludador" mencionado es "El impostor que aparenta curar o precaver la rabia u otros males, con el aliento, la saliva y con ciertas deprecaciones y fórmulas" (RAE, 1822: 733, 741; Labernia, 1861: 708, 727).

\section{Santiago del Bien}

En "Supersticiones de los peruanos" (Palma, 1968: 1430), afirma que los indígenas peruanos "reconocen un Santiago del bien, protector de sementeras y ganados, al cual también representan a caballo, blandiendo un alfanje, como para ahuyentar los espíritus malignos", como el santo patrón de España. Este es el Santiago el Bueno o Santiago del Bien.

\section{Santiago del Mal}

El tradicionista, en "Supersticiones de los peruanos" (Ibíd.: 1430), nos cuenta que los indígenas peruanos creían que las tempestades eran producidas "por un demonio llamado Santiago, que, como el santo patrón de España, anda por los 
aires montado en caballo blanco", que "echa chispas de fuego". Y "A él invocan los brujos para sus maleficios". Ese es el Santiago del Mal o Santiago el Malo.

\section{Sapo}

En "Anales de la Inquisición de Lima”, capítulo VI, (Ibíd.: 1259), refiere que "para causar la muerte del ganado, bastaba que una bruja colocase en el establo una trenza de sus cabellos o un sapo con tres maldiciones". Y "cuando una bruja quería hacerse amar de algún hombre, colocaba bajo el lecho de este un sapo con los ojos vendados, y si el hombre era casado, abandonaba a su mujer e hijos".

Asimismo, cuenta allí que:

En los aquelarres o reunión de brujos, en la noche del sábado, celebraba el diablo lo que llamaban la misa negra. Allí bautizaba el diablo niños y sapos. Los niños eran presentados, por la bruja su madrina, vestidos de terciopelo negro, y los sapos envueltos en terciopelo granate. (Ibídem)

\section{Soga de ahorcado}

En "Pancho Sales el verdugo" (Ibíd.: 747-748), menciona "un pedazo de cuerda de ahorcado, receta infalible para hacer fortuna". Y en "Contra pereza, diligencia” (Ibíd.: 1091), cuenta que un personaje, "Doña Quirina”, “era supersticiosa. No creía, ciertamente, que llevar consigo un pedacito de cuerda de ahorcado trae felicidad". Don Sebastián de Covarrubias, en 1611 , dice que "Tener soga de ahorcado, vulgarmente, se dize de los venturosos, que todo les sucede bien". Y "Las hechiceras dizen que para la bien querencia se aprovechan de estas sogas" (sic) (Covarrubias, 1611:31 vta.). 
La soga o cuerda de ahorcado fue un "Elemento de las preparaciones de Magia negra, al que se supone la virtud de alejar los peligros que pudiera correr la persona que guarde un trozo y de hacer que gane en el juego" (Maestri, 1956: 192).

\section{Velas}

En "Anales de la Inquisición de Lima", capítulo III, (Palma 1968: 1233), se refiere a la famosa beata Ángela Carranza, que fuera procesada por el Tribunal del Santo Oficio. Allí el tradicionista afirma que ella "Regalaba y vendía rosarios, velas, espadas, cuentos, campanillas y romero, como bendecidos por el cielo, y suponiendo que gozaban de ciertos privilegios".

\section{Viernes}

Palma, en "Anales de la Inquisición de Lima", capítulo VI (Ibíd.: 1259), cuenta que "Entre las creencias populares era muy general la de que en viernes no tenían las brujas poder para maleficiar al prójimo". Pero otros autores opinan lo contrario sobre el viernes: "Uno de los días escogidos por los brujos para celebrar sus aquelarres" (Maestri, 1956: 595). Y don Sebastián de Covarrubias, en 1611 , afirma que el viernes

Hacemos remembrança de la passión y muerte de nuestro Redemptor Iesu Christo, y con más particularidad, el día de Viernes Santo. Los viernes, por esta razón, son días de penitencia, y nos abstenemos de comer carne y grosura, y fuera de los religiosos, muchos seglares devotos añaden el ayuno (sic) (Covarrubias, 1611: 73). 


\section{Zahorí}

En "Anales de la Inquisición de Lima", capítulo IV, (Palma 1968: 1242), cuenta que el Tribunal de la Fe acusó al mulato limeño Nicolás de Araus y Borja por:

Ejercer la industria de descubrir por medio de varillas imanadas los tesoros enterrados. Preciábase de ser zahorí, esto es, de tener la virtud de ver lo que hay bajo el suelo. General creencia era es esos tiempos que todo el que nace en Jueves o Viernes Santo disfruta del privilegio de ser zahorí.

Antiguamente se escribía "çahorín don Sebastián de Covarrubias, en 1611, ofrece una extensa información, con esta ortografía, en su diccionario (Covarrubias, 161 1: 261 vta. - 262). La Real Academia Española, en 1914, define este término así: "Persona a quien el vulgo atribuye la facultad de ver lo que está oculto, aunque sea debajo de la tierra" (RAE, 1914: 1063).

\section{Bibliografía}

Covarrubias Orozco, S. de (1611). Tesoro de la lengua castellana, o española. Madrid: por Luis Sánchez, Impresor del Rey NS.

Labernia, P. (1861).Diccionario de la lengua castellana con las correspondencias catalana y latina, tomo II. Barcelona: Librería de Esteban Pujal.

Maestri, M. (1956). Diccionario de Ciencias Ocultas. Buenos Aires: Editorial Caymi.

Palma, R. (1968). Tradiciones Peruanas Completas. Madrid: Aguilar S. A. de Ediciones.

Raimondi, A. (1857). Elementos de Botánica aplicada a la Medicina y a la Industria. Segunda parte. Lima: Tipografía calle del Compás. 
Real Academia Española. (1817). Diccionario de la lengua castellana por la Real Academia Española. Madrid: Imprenta Nacional, quinta edición.

Real Academia Española. (1822). Diccionario de la lengua castellana por la Academia Española. Madrid: Imprenta Real, sexta edición.

Real Academia Española. (1914). Diccionario de la lengua castellana por la Real Academia Española. Madrid: Imprenta de los sucesores de Hernando, decimocuarta edición.

Recibido el 29 de noviembre del 2017 Aprobado el 20 de enero del 2018 